\title{
Properties of a Bulk-Fill Flowable Composite Resin with High Depth of Cure
}

\author{
Rimi Gill1', Brian J. Millar², Sanjukta Deb ${ }^{3}$ \\ ${ }^{1}$ Restorative Dentistry, King's College Hospital, London, UK \\ ${ }^{2}$ Department of Primary Dental Care, King's College London Dental Institute, London, UK \\ ${ }^{3}$ King's College London Dental Institute, King's College London, London, UK \\ Email: brian.millar@kcl.ac.uk
}

How to cite this paper: Gill, R., Millar, B.J. and Deb, S. (2017) Properties of a Bulk-Fill Flowable Composite Resin with High Depth of Cure. Open Journal of Stomatology, 7, 377-387.

https://doi.org/10.4236/ojst.2017.79032

Received: January 24, 2017

Accepted: August 25, 2017

Published: August 28, 2017

Copyright $\odot 2017$ by authors and Scientific Research Publishing Inc. This work is licensed under the Creative Commons Attribution International License (CC BY 4.0).

http://creativecommons.org/licenses/by/4.0/

(c) (i) Open Access

\begin{abstract}
Introduction: Dental composite resin materials are being increasingly used for a variety of purposes and more recently as a dentine replacement material. Objectives: SDR (Dentsply) is a flowable, high-resin composite material designed to minimise the effect of the high shrinkage through the use of a flexible monomer. However the resultant properties of this material may be a factor that affects the clinical performance. Methods. Tests were carried out on SDR and two other commonly used resin-based composite materials (Herculite XRV, Kerr and Spectrum TPH, Dentsply) including: depth of cure according to ISO 4049, degree of cure using Fourier Transform Infrared Spectroscopy (FTIR), compressive strength using a Universal testing Machine, water uptake, interaction with Coca-Cola ${ }^{\mathrm{TM}}$ and analysis of thermal transitions using Differential Scanning Calorimetry (DSC). Results. SDR exhibited a high depth of cure at $4.0 \mathrm{~mm}$ and no difference in degree of cure in comparison with the other two dental composites. Compressive strength results varied between materials but were significantly lower for SDR $(P<0.05)$. Water uptake was similar for all materials but elution was significantly greater for SDR and interaction with Coca-Cola showed greatest change for SDR. Conclusions: There are some statistically significant variations between the physical properties of the materials which are attributed to the monomer type and lower amount of filler in the flowable composite that may explain the published clinical outcomes.
\end{abstract}

\section{Keywords}

Comoposite, Bulk-Fill, SDR, Properties 


\section{Introduction}

Manufacturers are aiming to extend the range of use of composite resin and bulk-fill dentine replacement is a recent development with SDR (Smart Dentine Replacement, Dentsply) as a well-known example [1]. This material acts as lining materials as they require coverage with a regular composite [2]. SDR has an increased depth of cure due to increased translucency which can have an adverse impact on aesthetics in some clinical situations [3].

To overcome the higher shrinkage of these bulk-fill dentine replacement materials, which are flowable composite lining materials used in a thicker layer, a flexible polymer was developed for SDR [1]. This has the benefit of not translating the shrinkage stress to the tooth although SDR still exhibits higher shrinkage than conventional composite materials [4]. It is hypothesised that this will reduce the strengthening effect of the composite on the tooth, considered to be one of the benefits of adhesively bonded composite over previous materials such as amalgam.

While there are very few clinical trials available reporting on the outcomes of SDR the only two published clinical outcome studies show a statistically significantly greater incidence of cusp fractures over 2 years [5] [6]. It is clinically preferable to observe restoration fracture (more common with regular composite restorations) than the tooth fracture reported in both these clinical studies. One of the aims of this in-vitro study was to analyse the properties of the SDR material in comparison to regular composites to explain the observed clinical outcomes.

The reduced polymerisation stress on the tooth could also be due to a lower degree of polymerisation. This could be through either light attenuation by the composite leading to a reduced depth of cure than what is claimed, or if there is a reduced polymerisation. This study also aims to answer both those questions.

There is also a more general concern that high monomer resin content materials have disadvantages in terms of physical properties. The size of the particles in resin composites, along with the increased viscosity during setting, results in a high concentration of unreacted methacrylate monomer groups. This is due to an inability to diffuse (because of viscosity) to "reaction sites", in addition to the limit of light penetration or accessibility to the initiators and activators. These residual monomers may have a detrimental effect on the composite restoration as well as surrounding tissues.

The aim of this in vitro study was to investigate the properties of a bulk fill flowable resin restorative material.

\section{Materials \& Methods}

The materials evaluated in this study are detailed in Table 1 . The tests carried out in this study were:

1) Depth of Cure using ISO 4049 ( $n=3$ per group)

2) Degree of Cure using Fourier Transfer Infrared Spectroscopy ( $n=3$ per group) 
Table 1. The composite materials tested in this study: Spectrum (Dentsply), XRV Herculite (Kerr), SDR (Dentsply).

\begin{tabular}{|c|c|c|c|c|}
\hline Composite & Supplier & Shade (Batch) & Type & Composition \\
\hline $\begin{array}{l}\text { Spectrum TPH } \\
\text { (Total } \\
\text { Performance } \\
\text { Hybrid) }\end{array}$ & Dentsply & A3 $(60,605,203)$ & $\begin{array}{c}\text { Submicron } \\
\text { Hybrid }\end{array}$ & $\begin{array}{l}\text { Bis-GMA, Bis-EMA, TEGDMA, } \\
\text { Photoinitiators, Stabilizers, } \\
\text { Bariumaluminiumborosilicate (av. } \\
\text { particle size }<1 \mu \mathrm{m} \text { ), Highly } \\
\text { dispersed silicon dioxide } \\
\text { Inorganic fillers ( } 57 \% \text { by volume, } \\
\text { particles } 0.04-5 \mu \mathrm{m})\end{array}$ \\
\hline XRV Herculite & Kerr & $\begin{array}{c}\text { A3.5 Enamel } \\
(23,039)\end{array}$ & Micro-hybrid & $\begin{array}{c}\text { Bis-GMA, TEGDMA, Al-B-Si glass, } \\
\mathrm{SiO}_{2} \text { Inorganic fillers ( } 59 \% \text { by } \\
\text { volume, particles } 0.6 \text { microns) }\end{array}$ \\
\hline $\begin{array}{l}\text { Surefil SDR: } \\
\text { Smart Dentin } \\
\text { Replacement }\end{array}$ & Dentsply & $\begin{array}{c}\text { Universal } \\
(60,603,001)\end{array}$ & $\begin{array}{c}\text { Bulk Fill } \\
\text { Flowable Base }\end{array}$ & $\begin{array}{c}\text { UDMA, EBPDMA, TEGDMA, } \\
\text { Bariumaluminofluoroborosilicate \& } \\
\text { strontium aluminofluroborosilicate } \\
\text { glass, CQ, BHT }\end{array}$ \\
\hline
\end{tabular}

3) Compressive Strength ( $n=6$ per group)

4) Water Uptake ( $n=2$ per group)

5) Interaction with Coca-Cola ${ }^{\mathrm{TM}}(\mathrm{n}=3)$

6) Thermal Transitions (Tg) using Differential Scanning Calorimetry (DSC) $(\mathrm{n}=2)$

\subsection{Depth of Cure-ISO 4049}

Depth of cure was calculated according to the International Standard Organisation (ISO) 4049 standard as used in previous composite studies [7] [8] [9] [10]. In summary, disposable cylindrical curing depth tester moulds were used (i.cure, Dentsply) and sprayed with a lubricant (DAS Silicone Mould Release, Electrolube). The moulds had a constant width of $4 \mathrm{~mm}$ and depth of up to $8 \mathrm{~mm}$ depth. Manufacturer's recommendations were followed for each material. After light curing the uncured material was scraped away with a metal spatula and then the resulting length was measured using Vernier caliper ( $R S$ Components Ltd, Stock no: 613 - 959, metric 0 - $150 \mathrm{~mm}$ ) which was then divided by two to give the effective depth of cure. This was repeated three times for each material to obtain an average depth of cure.

\subsection{Degree of Cure-Fourier Transfer Infrared Spectroscopy (FTIR)}

To determine the degree of cure or the monomer conversion (DC\%) FTIR spectra for each material was recorded on a FTIR spectrometer (Spectrum One, Perkin Elmer). A sample of uncured material was placed flat onto the source spot and tested, followed by a similar amount of the cured material which had been ground into a powder using a pestle and mortar.

Spectra were obtained by conducing 8 scans at a resolution of $4 \mathrm{~cm}^{-1}$ and a 
wavelength range of $4000-650 \mathrm{~cm}^{-1}$ and the absorption at appropriate $\mathrm{C}=\mathrm{C}$ location peaks, aromatic and aliphatic, were recorded. Three repeats for each material were conducted and the mean degree of conversion (\%) calculated, according to the formula below:

$$
D C \%=\left[1-\frac{\text { Aliphatic Cured/Aromatic Cured }}{\text { AliphaticUncured/Aromatic Uncured }}\right] \times 100
$$

\subsection{Compressive Strength}

Cylindrical specimens were formed using a metal mould $(4 \mathrm{~mm}$ diameter $\times 6$ $\mathrm{mm}$ length) and the specimens were cured for 40 seconds on each side. 24 specimens each of XRV Herculite, Spectrum TPH and SDR were placed in glass vials, and one group of each were tested after 24 hours in air; aged for 10 days in air, 10 days in distilled water at $37^{\circ} \mathrm{C}$ and Coca Cola at $37^{\circ} \mathrm{C}$ The specimens were also weighed with the average weight for each material being: Spectrum $(0.166$ $\mathrm{g})$, Herculite $(0.162 \mathrm{~g})$, SDR $(0.148 \mathrm{~g})$. The specimens were tested on a universal testing machine (Instron 5569A) at a crosshead speed of $5 \mathrm{~mm} / \mathrm{min}$ to determine compressive strength.

\subsection{Water Uptake}

Two disc specimens were made for each group. The initial diameter, thickness and weight of each specimen were measured using a Vernier caliper and weighing balance to calculate the volume of each specimen. Each specimen was stored individually in a glass vial of $4 \mathrm{ml}$ of water pre-equilibrated at a temperature of $37^{\circ} \mathrm{C}$ in an incubator. The initial mass $\left(m_{0}\right)$ and subsequent weights $\left(m_{t}\right)$ were recorded at intervals $\left(_{t}\right)$ of: $15,60,90,120,180,240,300$ and 360 minutes on the first day and daily thereafter until equilibrium was reached. Once sorption equilibrium was reached $\left(m_{1}\right)$, materials were dehydrated in the same incubator until a constant mass $\left(m_{2}\right)$ was consecutively recorded (1 week). The water sorption and water solubility of each material $\left(\mu \mathrm{g} / \mathrm{mm}^{3}\right)$ was calculated using the formulas:

Water Sorption $(W s)=\frac{m_{2}-m_{3}}{V}$ and Water Solubility $(W s l)=\frac{m_{1}-m_{3}}{V}$

\subsection{Interaction with Coca-Cola ${ }^{\mathrm{TM}}$}

Cylindrical specimens were prepared and cured as before $(4 \mathrm{~mm}$ diameter $\times 6 \mathrm{~mm}$ length) and placed individually in glass vials containing $5 \mathrm{ml}$ of Coca-Cola ${ }^{\mathrm{TM}}(\mathrm{pH}$ $\left.=2.42,{ }^{\circ} \mathrm{C}=21.4\right)$. Vials were incubated at $37^{\circ} \mathrm{C} \pm 1{ }^{\circ} \mathrm{C}$ and specimens weighed daily for 5 days and then every other weekday for a month as before.

\subsection{Thermal Transitions (Tg)—Differential Scanning Calorimetry (DSC)}

To observe the thermal properties of the composite materials, DSC was used. The glass transition, crystallisation and melting temperature were recorded for the cured composites. 
Materials were cured and aged in two conditions: 24 hours in air or 6 weeks in $7 \mathrm{ml}$ of phosphate buffered saline (PBS) solution (in $\mathrm{g} / \mathrm{l}: \mathrm{NaCl}(8.0), \mathrm{KCl}(0.2)$, $\mathrm{Na}_{2} \mathrm{HPO}_{4}(1.15), \mathrm{KH}_{2} \mathrm{PO}_{4}(0.2)$ at $\left.\mathrm{pH} 7.3,37^{\circ} \mathrm{C} \pm 1^{\circ} \mathrm{C}\right)$. Each material was then ground using a marble pestle and mortar and $10-20 \mathrm{mg}$ was placed into the differential scanning calorimeter chamber (Jade DSC, Perkin Elmer) along with an empty reference pan. The chamber was initially chilled with liquid nitrogen to $-20^{\circ} \mathrm{C}$ and pure nitrogen $\left(\mathrm{N}_{2}\right)$ gas was introduced with an approximate gas flow rate of $20 \mathrm{ml} / \mathrm{min}$ to eliminate moisture. The heat flow up to $150^{\circ} \mathrm{C}$ was recorded in $\mathrm{mW}$ and plotted against temperature for two cycles.

As $\mathrm{Tg}$ is a temperature range, the value used for analysis was the "Half $\mathrm{Cp}$ Extrapolated" value. This is the point where the specific heat change is half of the change in the completed transition state. It was calculated by marking tangents to observed increases in heat flow using the Pyris Series (Perkin Elmer) Data Analysis software.

\section{Statistical Analysis}

The results obtained include mean results and standard deviation and for some, the significance of the results. $\alpha=0.05$, by use of one-way analysis of variance (ANOVA) carried out by Microsoft Excel programme and Tukey post-hoc Test using Smith's Statistical Package(SSP). ANOVA values are with 2 degrees of freedom, as calculated by $n-1$ where $n=$ number of samples; in the case of this study $\mathrm{n}=3$ (Herculite XRV, Spectrum TPH and SDR).

Water uptake and dissolution was not tested for ANOVA, due to the limited number of sample repeats, which would make any significant $p$ value less likely. $\mathrm{Tg}$ values were not statistically tested due to the nature of values obtained. $\mathrm{Tg}$ is a temperature range and two repeats on the same equipment following identical heating cycles do not show any variation.

\section{Results}

\subsection{Depth of Cure}

The composition of each of the composites is shown in Table 1. Table 2 details the depths of cure achieved, which were between the ranges of 1.9 (Herculite $\mathrm{XRV}$ ) to $4 \mathrm{~mm}$ with very little deviation from the mean, especially in all 3 repeats of the SDR flowable composite that had no variation within the sample

Table 2. Mean depth of cure (in $\mathrm{mm}$, to $3 \mathrm{sf} ., \mathrm{n}=3$ ) and Standard Deviation (2sf.) for each of the three restorative composite materials described in Table 2.

\begin{tabular}{cccc}
\hline & Herculite XRV & Spectrum TPH & SDR \\
\hline Mean & 1.87 & 2.42 & 4.00 \\
Standard Deviation & 0.02 & 0.02 & 0.00 \\
\hline
\end{tabular}

Table 2 Depth of Cure for the test materials. Spectrum TPH's and Herculite XRV exhibited significantly lower depth of cure than SDR $(P<0.05)$ but there were no significant difference between the other materials Herculite and Spectrum TPH. 
group. Herculite XRV had the lowest depth of cure $(1.87 \mathrm{~mm})$ and SDR the greatest $(4 \mathrm{~mm})$. The differences between materials depth of cure $(\mathrm{mm})$ was deemed statistically significant by one-way ANOVA $(P=0.00016)$. Post-hoc Tukey tests showed only Spectrum TPH's depths of cure was significantly lower than SDR $(P<0.05)$ but no significant difference between SDR and Herculite XRV or Herculite XRV and Spectrum TPH.

\subsection{Degree of Cure-Fourier Transform Infrared Spectroscopy (FTIR)}

Table 3 shows the results for the degree of cure for each material, calculated from the spectra to demonstrate differences observed between uncured and cured states. These differences were compared between the materials used however ANOVA demonstrated them as not statistically significant ( $P=0.652 \mathrm{sf}$.).

\subsection{Compressive Strength}

The results (Table 4) show the compressive strengths for the materials. With the exception of the Coca-Cola ${ }^{\mathrm{TM}}$ conditioning, Herculite XRV samples exhibited a decrease in compressive strength. All Herculite XRV samples, be it duration of ageing or the ageing condition, the mean compressive strength decreased from the control dry state testing (274 MPa). Conversely, Spectrum TPH (268 MPa)

Table 3. Mean degree of cure (DC \%, 3sf) and the standard deviation (SD) for each of the three materials derived from FTIR values of uncured and cured specimens of the same sample. $\mathrm{n}=3$.

\begin{tabular}{cccc}
\hline & Herculite XRV & Spectrum TPH & SDR \\
\hline Mean DC \% & 68.3 & 75.6 & 68.5 \\
Standard Deviation & 13.3 & 8.01 & 9.51 \\
\hline
\end{tabular}

Table 3 Degree of Cure of the composites using FTIR spectroscopy. No significant differences were noted.

Table 4. Compressive strength of the dental composites following aged in different storage media over 10 day.

\begin{tabular}{ccccc}
\hline \multirow{2}{*}{ Ageing Condition } & Composite Material & $\begin{array}{c}\text { Mean Compressive } \\
\text { Strength (MPa), 3sf. }\end{array}$ & $\begin{array}{c}\text { Standard Deviation } \\
\text { (SD), 2sf. }\end{array}$ & $\begin{array}{c}\text { P value, } \\
\text { 2sf. }\end{array}$ \\
\hline \multirow{2}{*}{ Air } & Herculite XRV & 274 & 15 & \\
& Spectrum TPH & 268 & 27 & 0.00013 \\
& SDR & 185 & 10 & \\
Distilled Water & Herculite XRV & 183 & 4.7 & \\
& Spectrum TPH & 263 & 9.3 & 0.015 \\
& SDR & 195 & 24 & \\
& Herculite XRV & 158 & 14 & \\
Coca-Cola $^{\mathrm{TM}}$ & Spectrum TPH & 179 & 11 & 0.0003 \\
& SDR & 193 & 6.6 & \\
\hline
\end{tabular}


exhibited an increase over time and in the ageing solutions. After 6 weeks of ageing, the mean compressive strengths had surpassed Herculite XRV's initial state.

Out of all three materials, SDR had the lowest mean compressive strengths ranging from $169 \mathrm{MPa}$ after 10 days in water to $198 \mathrm{MPa}$ after 6 weeks in Co$\mathrm{ca}-\mathrm{Cola}^{\mathrm{TM}}$. All of the findings for each ageing condition between materials were statistically significant $(P<0.05)$.

\subsection{Water Uptake}

The mean percentage changes in water uptake and elution of mass in water were calculated and shown in Table 5. Water uptake or elution of the material in water is minimal. Spectrum TPH showed the most resistance to any changes resultant of the water environment, with only $0.883 \%$ (3.sf) water uptake and $0.224 \%$ material loss, with low standard deviations, indicating little variance. SDR had the greatest elution in water with the greatest standard deviation.

\subsection{Dissolution in Coca-Cola ${ }^{\mathrm{TM}}$}

Coca-Cola ${ }^{\mathrm{TM}}$ was selected due to its common use and acidity. Figure 1 shows the

Table 5. Mean Values (\%) of Water Uptake and Elution in Water to 3 sf. after a cycle of hydration (18 days) and dehydration (12 days) of each material. $n=2$. Figure in brackets is the standard deviation.

\begin{tabular}{ccc}
\hline Material & Water Uptake (\%) & Elution in Water (\%) \\
\hline Herculite XRV & $1.42(0.62)$ & $0.23(0.33)$ \\
Spectrum TPH & $0.88(0.01)$ & $0.22(0.31)$ \\
SDR & $1.02(0.20)$ & $1.310(1.85)$ \\
\hline
\end{tabular}

Table 5 Water uptake and elution in water.

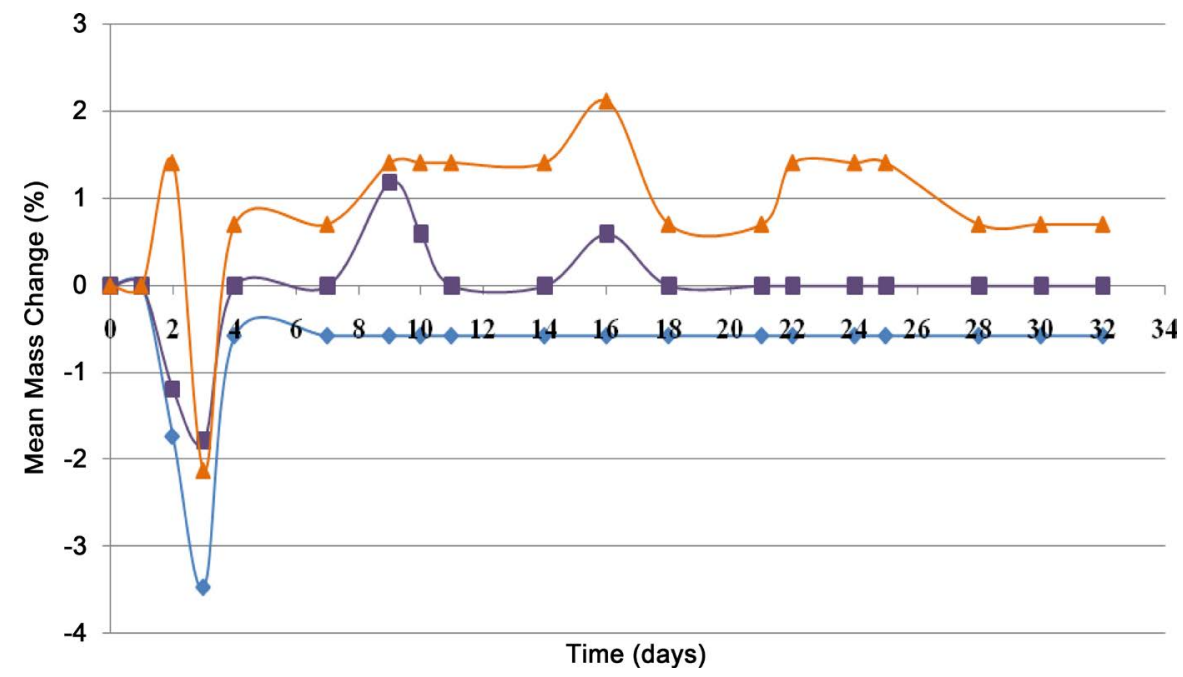

Figure 1. Mean changes in composite mass (\%) during dissolution in Coca-Cola ${ }^{\mathrm{TM}}$ for 33 days (stored at $37^{\circ} \mathrm{C} \pm 1^{\circ} \mathrm{C}$ ). $\mathrm{n}=2$. Herculite XRV (blue), Spectrum TPH (purple) and SDR (orange). 
differences in mass change over time, with the greatest change occuring in the first 4 days. Herculite XRV, despite being the most affected in the first 72 hours by dissolution effects, increased its mass and reached equilbrium at around day 7. However, the equilbrium mass reached was around $0.6 \%$ below its original mass $(0.173 \mathrm{mg})$.

In the first 72 hours, the weight of Spectrum TPH specimens had decreased by nearly $2 \%$ of its inital mass $(0.168 \mathrm{mg})$, before increasing and then fluctuating until reaching equilibrium was reached at about day 18. SDR showed the most exagerated effects of dissolution and took the longest to reach equilbrium at day 31. Whilst the other materials, experience mass loss at day 2, SDR material had gained mass, before a steep decrease just 24 hours later. Overall, SDR had the greatest mass gain and Spectrum TPH the greatest mass loss.

\subsection{Thermal Transitions (Tg)-Differential Scanning Calorimetry (DSC) (Table 6)}

The second heating cycle was used to derive these results, as it eliminates any fluctuating differences in the curve accountable to water loss. Overall, 4 weeks of ageing in PBS solution decreases the Tg value of all the materials.

\section{Discussion}

\subsection{Depth of Cure-ISO 4049}

The manufacturer's claim of a depth of cure of $4 \mathrm{~mm}$ for SDR is justified. This is largely due to the increased translucency of the material and low filler content. For a more detailed analysis, FTIR was used to determine the degree of cure.

A recognised problem with ISO 4049 is that it is relatively simple and subjective method. An alternative would be to use a penetrometer but the ISO test was carried out as it has been used in numerous publications [7] [8] [9] [10].

Table 6. Mean $\mathrm{Tg}$ values and standard deviation, $\mathrm{SD},\left({ }^{\circ} \mathrm{C}, 3 \mathrm{sf}.\right)$ after a second heating between $-20^{\circ} \mathrm{C}$ and $150^{\circ} \mathrm{C}$ of powdered samples $(n=3)$ of each composite material after 40 seconds of curing and in two conditions (48 hours in air and 4 weeks in PBS solution described in the methods).

\begin{tabular}{cccc}
\hline & & $\mathbf{4 8}$ hours & $\mathbf{4}$ weeks \\
\hline Herculite XRV & Mean & 41.3 & 38.3 \\
& SD & 2.78 & 1.79 \\
Spectrum TPH & Mean & 38.6 & 36.9 \\
& SD & 0.40 & 1.25 \\
SDR & Mean & 40.6 & 38.5 \\
& SD & 3.98 & 1.02
\end{tabular}

Table 6 Results for the mean Tg values derived using the "Half Cp Extrapolate" value. This shows the point on the DSC curve where a specific change in heat flow is half of the change overall during the thermal transition. 


\subsection{Degree of Cure-Fourier Transform Infrared Spectroscopy (FTIR)}

The DC was calculated by relating the height of the peak $1637 \mathrm{~cm}^{-1}$ to the intensity of different internal standard peaks $\left(1608 \mathrm{~cm}^{-1}\right)$, measured before and after polymerization. The degree of conversion was determined by measuring the absorbance intensities of the methacrylate $\mathrm{C}=\mathrm{C}$ absorbance peak at $1637 \mathrm{~cm}^{-1}$ and the C-C internal standard peak of the aromatic bis GMA or aliphatic UDMA at $1608 \mathrm{~cm}^{-1}$ and comparing ratios for the cured and uncured composites. The DC for each blend, polymerized and unpolymerized, was determined by the ratio of the absorbance peak corresponding to the carbon-carbon double bond (1637 $\mathrm{cm}^{-1}$ peak height) with that of the internal standard $\left(1715,1637\right.$, and $1608 \mathrm{~cm}^{-1}$ peak height). Herculite XRV, Spectrum TPH and SDR exhibited a similar degree of cure and the slight variation in degree of cure can be related to the slightly darker shades of Herculite XRV and Spectrum TPH, the difference in composition and the limitations of ATR-FTIR. A quick and effective polymerisation is especially useful to minimize monomer leakage; however the generation of heat due to the exothermic reaction and shrinkage also occurs with adverse effects on the tooth and pulp [11]. It is evident from the FTIR data $\left(1525 \mathrm{~cm}^{-1}, \mathrm{~N}-\mathrm{H}\right.$ deformation associated with - $\mathrm{CONH}$ group) and the composition information received from the manufacturer that SDR is the only composite in this study that contains urethane dimethacrylate [11]. The intense absorbance peak at around $1000 \mathrm{~cm}^{-1}$ is associated with the $\mathrm{Si}$-O-vibrational stretch, usually due to the presence of fillers.

\subsection{Compressive Strength}

The degree of monomer conversion, filler content and the type of monomer play an important role in resultant material properties and possible effects of unreacted monomer on adjacent tissues. It has been shown that SDR has a lower surface hardness than the other test materials which could be due to the low amounts of filler and extent of cure, which result in lower compressive strength [12]. The significantly lower surface hardness for SDR, as other bulk filling materials, requires to be covered by a regular composite material [2].

Ranking materials by their degree of cure: Herculite XRV, SDR and Spectrum $\mathrm{TPH}$, it is expected that the initial compressive strengths to be in this order as well. Surprisingly the order of materials compressive strength in air after 30 mins cure was: Spectrum TPH, Herculite XRV and SDR. This is due to low filler content in SDR, whilst for the other two materials tested it is primarily due to the degree of cure.

\subsection{Water Uptake}

No difference in water uptake between the materials was observed, however the significant loss in water from SDR could be explained by the high UDMA and lower filler contents. Despite the high degree of cure in SDR and Spectrum TPH 
and Herculite XRV, containing bis GMA polymers that possess higher sol fractions [13] the greatest elution in water was observed in SDR (1.31\% \pm SD:1.85). Therefore it is mainly attributable to the low filler content and high amount of polymer matrix.

\subsection{Interaction of the Dental Composites with in Coca-Cola ${ }^{\mathrm{TM}}$}

Coca-Cola is a widely consumed drink, which is acidic in nature, hence the effect on exposure to this drink on these composites were evaluated. The loss or gain in mass was monitored till equilibrium, a point where changes in weight stabilized. For instance with SDR, equilibrium occurred with a positive mass change, i.e. water sorption might have occurred, whereas with Herculite XRV the equilibrium there was with a negative mass change, i.e. loss of material.

The fact that SDR had the greatest mass gain and Spectrum TPH had the greatest mass loss is interesting. This is because mass gain could indicate water uptake from Coca-Cola ${ }^{\mathrm{TM}}$ occurred, supporting its $1 \%$ increase in the previous experiment. Whilst Spectrum TPH's mass loss demonstrates degradation occurred within the structure of the material potentially compromising its mechanical properties, as demonstrated by the decrease in compressive strength after 10 days. Additionally monomer leach also contributed to the mass loss. SDR is expected to show a loss simply due to the higher polymer component and since fillers can lower the interaction, the low filler also contributed.

\subsection{Thermal Transitions (Tg)—Differential Scanning Calorimetry (DSC)}

The $\mathrm{Tg}$ was recorded between $36.9^{\circ} \mathrm{C}-38.5^{\circ} \mathrm{C}$ for the composites, which is on the lower end of the acceptable ranges in the mouth since in vivo, the material must not soften, however the slight flexibility allows the material to adapt to occlusal forces and allow better adhesion around surfaces.

\section{Conclusion}

A disadvantage of SDR is that is cannot be used alone as a restorative product to completely fill deep cavities as it is a lining material rather than a restorative filling material. The reduced compressive strength and increased water uptake that can decrease the fatigue life may be factors that allow the increased flexion resulting in the cusp fractures observed for SDR in two clinical studies as tooth support is reduced unlike with regular restorative composites. The limitations of a laboratory study in attempting to predict clinical outcomes are well known as individual parameters are investigated in isolation under different conditions. However, the results from this laboratory study may explain the clinical outcomes observed.

\section{Conflict of Interests}

There is no conflict of interest. 


\section{References}

[1] Dentsply (2009) SDR Smart Dentin Replacement. Scientific Compendium Product Manual Guide.

[2] Ilie, N., Bucuta, S. and Draenert, M. (2013) Bulk-Fill Resin-Based Composites: An In Vitro Assessment of Their Mechanical Performance. Operative Dentistry, 38, 618-625. https://doi.org/10.2341/12-395-L

[3] Pedalino, I., Hartup, G.R. and Vandewalle, K.S. (2015) Depth of Cure of Bulk-Fill Flowable Composite Resins. General Dentistry, 63, e28-34.

[4] Jang, J.H., Park, S.H. and Hwang, I.N. (2015) Polymerization Shrinkage and Depth of Cure of Bulk-Fill Resin Composites and Highly Filled Flowable Resin. Operative Dentistry, 40, 172-180. Epub 2014 Aug 19. https://doi.org/10.2341/13-307-L

[5] Van Dijken, J.W. (2013) Randomised 2-Year Follow-Up of Posterior Bulk-Filled Resin Composite Restorations. Presented at the 46th Meeting of the Continental European Division of the International Association for Dental Research with the Scandinavian Division (NOF) Florence. Available from http://www.dentsply.co.uk/products/restorative/composites/SDR (accessed September 2014).

[6] McGuirk, C., Hussain, F. and Millar, B.J. (2017) Survival of Direct Posterior Composites with and without a Bulk Fill Base. European Journal of Prosthodontics and Restorative Dentistry, 25, 3.

[7] Dunne, S.M., Davies, B.R. and Millar, B.J. (1996) A Survey of the Effectiveness of Dental Light-Curing Units and a Comparison of Light Testing Devices. British Dental Journal, 180, 411-416.

[8] Dunne, S.M. and Millar, B.J. (2008) Effect of Distance from Halogen and Plasma Light Sources on Depth of Cure of Composite Resin. Primary Dental Care, 15, 147-152. https://doi.org/10.1308/135576108785891150

[9] Aravamudhan, K., Rakowski, D. and Fan, P.L. (2006) Variation of Depth of Cure and Intensity with Distance Using LED Curing Lights. Dental Materials, 22, 988-994. https://doi.org/10.1016/j.dental.2005.11.031

[10] Moore, B.K., Platt, J.A., Borges, G., Chu, T.-M.G. and Katsilieri, I. (2008) Depth of Cure of Dental Resin Composites, ISO 4049 Depth and Microhardness of Types of Materials and Shades. Operative Dentistry, 33, 408-412. https://doi.org/10.2341/07-104

[11] Young, A.M., Rafeeka, S.A. and Howlett, J.A. (2004) FTIR Investigation of Monomer Polymerisation and Polyacid Neutralisation Kinetics and Mechanisms in Various Aesthetic Dental Restorative Materials. Biomaterials, 25, 823-833. https://doi.org/10.1016/S0142-9612(03)00599-4

[12] Floyd, C.J.E. and Dickens, S.H. (2006) Network Structure of Bis-GMA- and UDMA-Based Resin Systems. Dental Materials, 22, 1143-1149. https://doi.org/10.1016/j.dental.2005.10.009

[13] Abed, Y.A., Sabry H.A. and Alrobeigy, N.A. (2015) Degree of Conversion and Surface Hardness of Bulk-Fill Composite versus Incremental-Fill Composite. Tanta Dental Journal, 12, 71-80. https://doi.org/10.1016/j.tdj.2015.01.003 
Submit or recommend next manuscript to SCIRP and we will provide best service for you:

Accepting pre-submission inquiries through Email, Facebook, LinkedIn, Twitter, etc. A wide selection of journals (inclusive of 9 subjects, more than 200 journals)

Providing 24-hour high-quality service

User-friendly online submission system

Fair and swift peer-review system

Efficient typesetting and proofreading procedure

Display of the result of downloads and visits, as well as the number of cited articles Maximum dissemination of your research work

Submit your manuscript at: http://papersubmission.scirp.org/

Or contact ojst@scirp.org 